\title{
Arbor
}

\section{Una aproximación a la emigración española hacia Europa en los años cincuenta desde la perspectiva de la Organización Sindical Española $(\mathrm{OSE})^{1}$}

\section{Ramón Baeza Sanjuán}

Arbor CLXX, 669 (Septiembre 2001), 181-199 pp.

A partir de la primera mitad de la década de los años cincuenta comenzó un nuevo proceso migratorio, favorecido por la deleznable situación económica y social que atravesaba España. El destino de aquellos que buscaban una oportunidad laboral más allá de las fronteras estuvo preferentemente en países de Europa occidental. Desde un primer momento la Organización Sindical Española (OSE) pretendió jugar un papel protagonista en la ordenación del proceso, no dudando para ello en enfrentarse con otras estructuras de la administración española. Su objetivo fue conservar en el extranjero la función de encuadramiento y control de los trabajadores que tenía asignada en España. Tras esta pretensión también se escondía la voluntad de mantener la mayor influencia posible en la siempre inestable relación de poder entre las distintas fuerzas sustentadoras del régimen franquista. De esta forma, pugnando con los ministerios de Trabajo y Exteriores, la OSE consiguió conquistar un espacio propio en la definición y gestión de la política migratoria española. Participó, defendiendo intereses propios, en las negociaciones de acuerdos bilaterales reguladores de la emigración. También, a través de las agregadurías laborales, desarrolló una importante actividad de asesoramiento, asistencia y control político de los emigrantes. Por último, en ciertas ocasiones, intentó utilizar a los emigrantes españoles como instrumentos de presión sobre terceros Estados. 


\section{La Organización Sindical ante el comienzo de la emigración española a Europa}

Durante la década de los cincuenta España fue un país que atravesó diferentes periodos de quiebra técnica, al borde la bancarrota y la suspensión de pagos. Carente de divisas con las que hacer frente a los intercambios comerciales con el exterior, con un tejido industrial raquítico y obsoleto, y una agricultura ineficaz cuyos productos se depreciaban constantemente en relación con los productos manufacturados. La situación social corría pareja a la crisis económica. En 1958 la renta de los asalariados agrícolas y de los pequeños propietarios era todavía inferior a la existente antes del comienzo de la Guerra Civil. Cada año decenas de miles de personas abandonaban el campo, en dirección a las grandes ciudades en busca de la oportunidad que el medio rural les negaba. En buena medida, los componentes de este éxodo incrementaban los cinturones de miseria de las principales urbes industriales, donde el desempleo y la falta de vivienda definían las líneas maestras de la realidad social ${ }^{2}$. Entre 1957 y 1959 el coste de la vida se incrementó el $40 \%$.

La situación española contrastaba con la de sus más próximos vecinos de Europa occidental -exceptuando Portugal- quienes, tras superar las más dramáticas secuelas de la Segunda Guerra Mundial, en los años cincuenta disfrutaban de un crecimiento económico sostenido y de la puesta en práctica de sistemas de protección social que no tenían precedentes. Francia, a pesar de las convulsiones políticas internas y de las insurrecciones armadas que tenían lugar en alguna de sus colonias, gozaba de un rápido y continuo crecimiento económico favorecido por la iniciativa gubernamental conocida por Tercer Plan de Modernización y Equipamiento. Italia pasó de exportar mano de obra a una situación de pleno empleo, especialmente en la mitad norte del país. La República Federal de Alemania se reidustrializaba a gran velocidad, lo que era tanto más notable teniendo en cuenta el nivel de pérdidas humanas y materiales que cosechó durante la contienda. La economía de Bélgica crecía con enorme rapidez, sustentada sobre la extracción de carbón y la producción siderúrgica, y favorecida por un desarrollo comercial que se benefició de los limitados daños que sufrió el país durante la ocupación y retirada de las tropas nazis.

El crecimiento económico sostenido de Francia, Italia, Alemania y Bélgica -a los que habría que añadir Suiza, Países Bajos y el Reino Unido- provocó interesantes transformaciones en la estructura social de aquellos países. Una parte significativa de sus trabajadores aban- 
donaron las actividades más duras, peor remuneradas o más peligrosas, aprovechando las nuevas oportunidades laborales que ofrecía un sector terciario en continua expansión. En consecuencia, determinados sectores productivos -especialmente la minería y la agricultura-tuvieron que recurrir a mano de obra extranjera para garantizar su pervivencia.

A la luz de la situación descrita, el panorama económico y social de la Europa occidental parecía claramente complementario: España disponía de un importante volumen de mano de obra incapaz de ser aprovechado por la débil estructura productiva del país, al tiempo que los Estados circundantes necesitaban trabajadores para garantizar la continuidad de su desarrollo económico. Favorecer la emigración se alzaba como la conclusión lógica, beneficiosa para los intereses de unos y otros.

Desde el Estado español, la adopción de semejante iniciativa no dejaba de provocar severas contradicciones. La exportación masiva de mano de obra era el reconocimiento implícito del fracaso de un modelo de desarrollo económico y social que se había definido fundamentalmente como nacional y, por ello, no eran pocos quienes, por principio y desde las filas del propio Régimen, se oponían a ella. De hecho, el marco jurídico vigente dificultaba las posibilidades reales de emigrar al extranjero ${ }^{3}$. Y, más allá de impedimentos normativos, el entramado institucional implicado en algún momento en el proceso de regulación de la emigración ${ }^{4}$ carecía de coordinación, provocaba continuos conflictos de competencias, aplicaba criterios que se contradecían entre sí, y se caracterizó por continuos solapamientos que dificultaban, aún en mayor medida que las restricciones legales, las iniciativas de todos aquellos que decidían emprender la búsqueda de un trabajo más allá de las fronteras españolas. Todavía en 1960 el Instituto de Estudios Políticos ofrecía esta devastadora imagen de los instrumentos de ejecución de la política migratoria con los que el Estado se había dotado:

«Es, sin embargo, mucho lo que falta, desde una política diplomática encauzada en la materia, hasta una acción organizada en el exterior con caracteres de eficacia... Y, más todavía, pudiera pensarse que el fallo fundamental radica en que las organizaciones actuantes hoy no comprenden su posición instrumental en relación a la práctica de una acción conjunta y no se hallan ni centradas en su misión, ni regladas en sus facultades, ni limitadas en su autonomía. Así es como la emigración se produce como un tremendo desacorde conjunto, falto de compás y de dirección.... ${ }^{5}$

A pesar de las reticencias políticas y las disuasiones administrativas, conforme avanzaban los años cincuenta, la emigración se impuso como 
una necesidad insoslayable para muchos miles de españoles que, expulsados del campo, tampoco encontraban acomodo en las ciudades industriales. Y también para un Estado al que las rentas de los emigrantes contribuían a incrementar el magro volumen de divisas del que disponía, que le resultaban imprescindibles para acometer el desarrollo del país y que otros sectores económicos no conseguían aportar. $\mathrm{Y}$ tampoco debe menospreciarse el valor de la emigración como factor de estabilidad social, exportando trabajadores que, de otra manera, estarían condenados a incrementar las bolsas de desempleo, siempre susceptibles de generar manifestaciones de descontento difícilmente controlables incluso por un régimen autoritario ${ }^{6}$.

La Organización Sindical pretendió, en primer lugar, no quedar marginada como consecuencia de los cambios económicos, sociales y políticos que esta nueva situación pudiera provocar. Pero también sacar provecho, buscando incrementar su influencia en el siempre inestable equilibrio existente entre las diferentes fuerzas que sustentaban al régimen franquista. De esta manera intentó acaparar las competencias derivadas del nuevo éxodo de trabajadores españoles al extranjero, solicitando la creación de un organismo sindical especialmente dedicado a ese cometido ${ }^{7}$. Sus aspiraciones no carecían de justificación: por Ley de 10 de febrero de 1943 a la OSE le correspondía ejercer las funciones de encuadramiento de la población laboral, además de la orientación y estadística de los movimientos migratorios internos. No parecía incoherente reclamar esa misma responsabilidad para la emigración al extranjero. Pero sus aspiraciones chocaron con la firme oposición de los ministerios de Trabajo y Exteriores: el primero de ellos defendía un espacio político propio cuyas fronteras con las actividades desarrolladas por la OSE eran más que difusas; desde el Palacio de Santa Cruz se intentaba evitar que el verticalismo incrementara aún más su presencia exterior después de la constitución de las primeras agregadurías sindicales/laborales en 1953. Finalmente la Organización Sindical tuvo que admitir su derrota al decidirse la creación del Instituto Español de Emigración (IEE) que fue adscrito definitivamente al Ministerio de Trabajo ${ }^{8}$. El Instituto tendría por cometido erradicar el paro y combatir el subempleo, facilitando el acceso a un puesto de trabajo en el extranjero a aquellos españoles que lo demandaran.

Sin embargo, la aparente victoria de Trabajo ha de ser matizada. Con el fin de no multiplicar innecesariamente las estructuras administrativas y el aparato burocrático, el Instituto Español de Emigración se vió obligado a recurrir, en territorio español, a la red de Oficinas Sindicales de Encuadramiento y Colocación -dependientes de la Vice- 
Una aproximación a la imigración española hacia Europa...

secretaría de Ordenación Social de la DNS- como instrumento de información, gestión y selección de personal a nivel local y comarcal. En el exterior, a los agregados laborales designados por la Delegación Nacional de Sindicatos se les añadió la responsabilidad de delegados del IEE. Por lo tanto, una parte considerable de la ejecución de las competencias atribuidas al organismo autónomo dependiente del Ministerio de Trabajo fueron puestas en práctica por sus adversarios en la administración del Estado. Tal entramado de dependencias funcionales y orgánicas -entrevelado de lealtades políticas- desembocó en continuos enfrentamientos y conflictos de competencias que trataron de solventarse infructuosamente hasta ya entrada la década de los sesenta.

$\mathrm{Al}$ mismo tiempo que la Organización Sindical pugnaba por alzarse con el control sobre la política migratoria, sus ideólogos comenzaron la labor de legitimación teórica de esta nueva realidad. Tácitamente se admitía como un fracaso que España fuera incapaz de aprovechar buena parte de sus recursos humanos en su propio territorio, pero, aceptando este hecho consumado con notable naturalidad, abordaron la cuestión de qué función debían desempeñar las administraciones públicas a partir de ese momento. Prevaleció una coincidencia básica: el Estado no podía desentenderse de la suerte que corrieran sus ciudadanos, incluso si éstos habían decidido traspasar las fronteras nacionales. En primer lugar, porque una colonia carente de atención era una fuente de desprestigio exterior del Régimen, cuyas repercusiones serían difícilmente subsanables ${ }^{10}$. Pero no todo eran filántropicas preocupaciones. El Servicio de Relaciones Exteriores de la DNS advirtió en reiteradas ocasiones sobre la potencial dimensión que podían alcanzar las repatriación de los ahorros de los trabajadores en el extranjero si la emigración se encauzaba con un mínimo de orden y eficacia. Y tampoco menospreciaron un aspecto aparentemente menor, aunque factor imprescindible para el desarrollo económico de un país y del que la OSE albergaba las competencias: la emigración como fuente de capacitación profesional en las más modernas tecnologías.

De esta manera, la Organización Sindical concedió tal importancia al renovado proceso migratorio, que hizo de él uno de los principales centros de sus actividades exteriores, desde que las inició al principio de los años cincuenta.

La tarea emprendida hubo de afrontar no pocas dificultades. La primera de ellas fue constatar el desconocimiento absoluto del número de españoles que se encontraban trabajando fuera de España y la ausencia de un registro pormenorizado de salidas o entradas. Tal situación podía parcialmente explicarse por la práctica generalizada de 
abandonar irregularmente el país, mediante el recurso a visados turísticos o careciendo de toda documentación, producto de las dificultades para obtener los diferentes permisos necesarios, tal y como se señaló con anterioridad. De esta forma, durante no pocos años, se aceptaron como oficiales las estimaciones que los agregados laborales se veían obligados a realizar, sin medios fiables y, en no pocos casos, al mismo tiempo en el que se incorporaban a unos destinos que les eran en gran medida ajenos. Existe, no obstante, un consenso básico que permite afirmar que, desde el comienzo de la década de los cincuenta, la emigración se dirigió principalmente hacia Europa occidental, sustituyendo al tradicional éxodo transatlántico. Francia y Bélgica inicialmente, Reino Unido, Alemania y Suiza después, fueron los países que recibieron un mayor número de trabajadores españoles.

\section{El papel de la OSE en los acuerdos bilaterales reguladores de la emigración}

La decidida voluntad de la OSE de desempeñar un papel protagonista en la política migratoria le llevó a participar activamente en las negociaciones de acuerdos laborales bilaterales con otros países. Estas negociaciones, en las que la presidencia de la delegación española recayó habitualmente sobre el Ministerio de Asuntos Exteriores (participando también delegados de los ministerios de Trabajo, Industria y Comercio), se prodigaron a partir de la segunda mitad de los años cincuenta. La representación de la OSE estuvo habitualmente compuesta por dirigentes de la Oficina de Encuadramiento y Colocación, de la Obra Sindical de Previsión Social y del Servicio de Relaciones Exteriores de la DNS. A través de los distintos acuerdos pretendió establecerse un marco jurídico regulador de las condiciones de trabajo de los españoles que se desplazaran al extranjero, especialmente en aquellos aspectos relacionados con el establecimiento de instrumentos de transferencias de fondos y la coordinación de los sistemas de seguridad social. En suma, se pretendió sentar las mínimas bases que facilitaran que el nuevo éxodo migratorio, dirigido esta vez hacia Europa, se realizaba con unas garantías mínimas para los trabajadores y con un provecho parejo para el Estado.

Los acuerdos alcanzados fueron de muy diversa índole, según la situación concreta de cada país y la voluntad de las contrapartes gubernamentales. La OSE desempeñó un papel especialmente destacable en las negociaciones con Bélgica. De hecho, aunque desde 1951 la embajada de España en Bruselas trasmitió en reiteradas ocasiones al 
Ministerio de Asuntos Exteriores la necesidad de negociar un acuerdo laboral, no se adoptó iniciativa alguna en tal sentido hasta que una delegación de la DNS, desplazada a varios países con el cometido de estudiar instrumentos para la prevención y tratamiento de la silicosis, constató la situación de total desamparo en la que se encontraban los mineros españoles en territorio belga y dió la voz de alarma: «en definitiva, y como resumen de lo expuesto, se llega al convencimiento de que el gobierno español, por todos los medios a su alcance debe controlar el desplazamiento de nuestros mineros a Bélgica y someterlos a una acción tutelar que como hombres y como españoles merecen» ${ }^{11}$. En el interesante informe elaborado por la OSE puede comprobarse que la preocupación no se sustentaba únicamente sobre sentimientos filantrópicos: ante las discriminaciones que sufrían respecto a los mineros de otros países (especialmente italianos) con los que Bélgica había suscrito acuerdos, un número significativo de españoles (atendiendo a los propios consejos de la administración y organizaciones sindicales belgas), demandaban el estatuto de refugiado político que les otorgaba mayores beneficios sociales, lo que ponía en evidencia a las autoridades españolas y proporcionaba no pocos réditos políticos a los exiliados antifranquistas.

Las inquietudes expuestas se saldaron en 1957 con la firma de diversos acuerdos que abarcaban desde un convenio general sobre seguridad social hasta la coordinación de ciertos procedimientos administrativos de indudable interés, como la redacción de formularios en las lenguas oficiales de ambos Estados. No cayó en el olvido la querida reivindicación española de simplificación de los instrumentos de transferencias de fondos. Fue, sin embargo, un asunto de importancia aparentemente menor el que posiblemente fue recibido con mayor regocijo en el seno de la OSE. Desde el momento de la entrada en vigor del convenio hispano-belga, los trabajadores que quisieran acogerse a sus beneficios -y hay que suponer que serían la práctica totalidad- deberían formalizar su situación ante la embajada española. Esta nueva situación facilitaría notablemente su control (especialmente, como se abordará más adelante, por parte de la agregaduría laboral) y restaría influencia a los grupos de exiliados que hacían proxelitismo entre los trabajadores españoles. Por último, también se alcanzaron acuerdos específicos para el sector de la minería que favorecieron una incorporación masiva de españoles a las cuencas carboníferas belgas, abandonadas por los mineros italianos a causa de los muchos accidentes provocados por la deficiente seguridad de las explotaciones.

En el caso de las negociaciones con Francia, celebradas en Madrid durante el mes de marzo de 1956, la DNS también jugó un destacado 
papel a través del agregado laboral en París. El agregado -José Sanz Catalán- desde el principio se destacó por ser el principal interlocutor frente a los representantes de la Oficina Nacional de Inmigración (ONI) francesa. También se vió obligado a mediar en los enfrentamientos que se produjeron en el seno de la delegación española, entre sus colegas del Servicio Nacional de Encuadramiento y Colocación de la DNS y los delegados del Instituto Español de Emigración.

A mediados de los años cincuenta, la emigración clandestina se había transformado en uno de los principales problemas bilaterales entre España y Francia. Cada año, miles de españoles atravesaban ilegalmente la frontera en busca de trabajo, utilizando intermediarios que cobraban generosamente sus servicios y se desentendían de los innumerables problemas que surgían con posterioridad. Los servicios consulares españoles y las autoridades galas de inmigración apenas tenían capacidad para dar respuesta al enorme cúmulo de incidentes que se derivaban de una tal situación ${ }^{12}$. La actualización del obsoleto Tratado Franco-Español de Trabajo y Asistencia, de 1932, parecía un objetivo compartido por los dos Estados.

Tras la conclusión de las negociaciones, los textos finalmente adoptados obligaban a Francia a concretar anualmente el número de trabajadores dispuestos a ser aceptados, normalizar contratos, pormenorizar las ofertas y garantizar el pleno respeto de los derechos laborales de una mano de obra cuyas singulares características favorecían su sobreexplotación. Por su parte, la administración española se comprometía a colaborar en el reclutamiento de trabajadores y a eliminar las tradicionales trabas y restricciones para la concesión de visados. Significativamente, uno de los mayores problemas prácticos derivados de la puesta en práctica del acuerdo estuvo en la repatriación de los ahorros de los emigrantes. Inicialmente la administración española consiguió imponer su criterio mediante el establecimiento de tarjetas de giro o talonarios de mandato, puestos a disposición de los emigrantes. Pronto las autoridades francesas se percataron de que, mediante este sistema, el Estado español recaudaba subrepticiamente cerca de un $20 \%$ de los capitales transferidos. Y la asociación simbiótica de la Organización Sindical y la Iglesia católica tampoco fue a la zaga: los capellanes sindicales, cuyo cometido consistía en auxiliar espiritualmente a los emigrantes, transferían directamente a los familiares en España los ahorros encomendados... con una pequeña merma del $18 \%$ en concepto de comisión por el cambio de divisas. Tal situación encrespó los ánimos de las autoridades galas quienes sancionaron a la administración española y exigieron un inmediato cambio de métodos, provocando 
el consiguiente regocijo entre la importante colonia de activos exiliados antifranquistas que residían en Francia.

Como en el caso de Bélgica, la conclusión de un acuerdo con Francia contribuyó a hacer aflorar un buen número de emigrantes en situación ilegal, animando, al mismo tiempo, a que nuevas oleadas de españoles pusieran rumbo hacia el país vecino. Los problemas se multiplicaron dejando rápidamente obsoletos los acuerdos alcanzados en 1956. De inmediato comenzaron a negociarse nuevos acuerdos complementarios, prestando una especial atención a los colectivos más olvidados en el texto anterior $\mathrm{y}$, de forma particular, a los emigrantes que residían permanentemente en Francia. En esta ocasión, también el agregado laboral desempeñó una labor destacada.

Las iniciativas emprendidas hacia Alemania en las que participó la OSE fueron de un inferior calado que las descritas hasta este momento, si bien vieron la luz ya al principio de la década. Comenzaron con la pretensión de que se reanudaran las indemnizaciones a los españoles que trabajaron en las empresas del III Reich, interrumpidas desde el final de la II Guerra Mundial. También en 1952 se firmó un convenio de intercambio de trabajadores con la voluntad de mejorar la cualificación profesional, si bien la Organización Sindical puso particularmente sus esperanzas en que contribuyera, sobre todo, a tender puentes con las autoridades y organizaciones laborales alemanas. El aprovechamiento de este convenio -bastante modesto en sí mismofue extremadamente limitado: en sus primeros tres años de vida apenas fueron tramitados doscientos expedientes, debido a que los trabajadores españoles demostraban una gran dificultad para cumplir los requisitos exigidos y los alemanes no se sentían atraídos por las modestas condiciones de trabajo que les eran ofrecidas en España. Tan escasa respuesta dejó en una comprometida situación a los jerarcas verticalistas que se creyeron en la obligación de continuar, en los años siguientes a la firma, la difusión de las bondades del convenio. La respuesta continuó siendo tan escasa que, finalmente, la DNS optó por que los beneficiarios fueran reclutados entre los alumnos aventajados de los centros dependientes de la Obra Sindical de Formación Profesional.

Tras esta decepcionante experiencia, en los últimos años de la década, la OSE participó en otras negociaciones con Alemania circunscritas al ámbito laboral. Entre ellas cabría destacar las que concluyeron con el acuerdo general de seguridad social, el acuerdo regulador de la emigración temporal de peones a la región del Ruhr y un nuevo acuerdo tendente a fomentar la especialización profesional de obreros españoles en empresas alemanas. 
De menor trascendencia fueron los acuerdos suscritos con Italia y Suiza. Los firmados con este último país tenían como objeto primordial atajar la oleada de españoles que llegaban con pasaporte turístico, residiendo y trabajando en la ilegalidad. Es necesario reconocer, no obstante, que la participación de la Organización Sindical en este caso fue poco relevante.

\section{La OSE como instrumento de asesoramiento, asistencia y control político de la emigración española a través de las agregadurías laborales}

La conclusión de acuerdos bilaterales contribuyó a regular la precaria situación de muchos emigrantes pero, además, alentó a un número considerable de españoles a buscar trabajo en el extranjero. Ya en la década de los cincuenta el éxodo laboral hacia algunos países europeos alcanzó una notable dimensión.

Esta situación planteó con insistencia la cuestión ya mencionada con anterioridad sobre las responsabilidades y compromisos que un Estado conserva hacia sus nacionales, aun si éstos se encuentran más allá de sus fronteras. El trabajador español llegaba a un país extraño careciendo, en la inmensa mayoría de las ocasiones, incluso de un conocimiento mínimo de la lengua allí hablada. Su introducción en el mercado de trabajo y en la sociedad que le acogía, la observancia del cumplimiento de las condiciones pactadas en convenios y contratos o la mediación en conflictos en los que pudiera verse involucrado, resultaban pruebas arduas que individualmente se afrontaban con dificultad. La OSE, a través de sus agregados laborales, contribuyó a asesorar y asistir a los emigrantes en sus problemas cotidianos, aprovechando estos servicios también para alcanzar otros objetivos de no poco calado político: controlar a la colonia española y reforzar las relaciones institucionales con las administraciones de otros Estados. Claramente lo expresaba el Jefe del Servicio de Relaciones Exteriores de la DNS a Francisco Franco:

«No podemos dejar dispersos a los españoles deslizados por la emigración. Son hombres de España que debemos conducir y cuidar a través de los sindicatos a los cuales pertenecen, no dejándoles dispersos y llevando hasta ellos el recuerdo, consejo y presencia de sus camaradas. La emigración debe ser canalizada en su naturaleza y aspecto sindical ${ }^{13}$

Así ocurrió en Bélgica, donde la entrada en vigor de los acuerdos obligó al agregado laboral a divulgar sus contenidos entre los emigrantes 
y facilitar la solución de todas aquellas cuestiones ligadas a su interpretación. De especial relevancia fue la tarea de alentar las reclamaciones individuales de cientos de trabajadores -en su mayoría mineros- que les permitieran obtener el reconocimiento de ciertos derechos que en los acuerdos se contemplaban con caracter retroactivo. También hay que destacar la actividad de la agregaduría cuando, a finales de la década, el estallido de una crisis económica desembocó en el despido de un número importante de mineros españoles. Todos estos esfuerzos efectuados desde la agregaduría no fueron en vano, viéndose recompensados con el incremento de su influencia sobre una colonia que tradicionalmente se había caracterizado por su oposición al Régimen y sus recelos hacia la representación del Estado en Bélgica.

Las tareas de asesoramiento legal realizadas por la agregaduría laboral alcanzaron también una enorme envergadura en Francia, donde los trabajadores españoles se contaban por cientos de miles. La mayor parte de aquellos que demandaron consejo y asistencia fueron trabajadores agrícolas de temporada, ocupados en arrozales, viñedos y campos de remolacha. Tal fue el número de empleados en el campo francés que llegó a constituirse una Comisión de Conciliación, compuesta por representantes de la administración y de la asociación patronal agraria francesas y, de parte española, por representantes de la DNS con estatuto de adjuntos a la agregaduría laboral. Pero la tarea no se circunscribió exclusivamente al ámbito agrícola, alcanzando también a las principales industrias, donde se concentraban un número significativo de españoles a los que se pretendió hacer partícipes de las líneas directrices de los acuerdos alcanzados. Entre las actividades destacables de la agregaduría laboral en París también estuvo la difusión de información sobre la concesión de subsidios para los emigrantes de mayor antigüedad, de forma que pudieran regresar a España a disfrutar de los que previsiblemente serían sus últimos años de vida.

De igual forma el agregado laboral en Berna hizo del asesoramiento y asistencia a los emigrantes una de sus principales tareas. A tal efecto visitó continuamente explotaciones agrarias y fábricas de los cantones donde se concentraban españoles, desde el convencimiento de que los principales problemas que les afectaban procedían de su falta de información. Sin embargo, a diferencia de sus homólogos en Francia y Bélgica, no consiguió un nivel aceptable de interlocución con las autoridades del país, acusando a la administración helvética de una falta absoluta de voluntad política para establecer cauces de diálogo permanentes.

Una mención diferenciada debe hacerse a la atención a los españoles trabajando en Gran Bretaña. Allí se creó una oficina de atención integral 
que debería asistir a los emigrantes desde su llegada, ayudando a la formalización de documentos, orientando en la búsqueda de alojamiento y elaborando un censo. Esta atención inicial debería continuarse facilitando la inserción en el mercado de trabajo británico, aconsejando los sectores con mayor demanda de empleo e informando de los derechos laborales pertinentes. Tan elaborado plan fue un fracaso que se saldó con una deficiente asistencia a los emigrantes. Las raíces de este frustrado intento seguramente hay que buscarlas en el modelo organizativo puesto en práctica: la oficina diseñada debía trabajar bajo las órdenes conjuntas de la agregaduría laboral y del consulado, producto de un acuerdo interministerial elaborado conjuntamente por Gobernación, Exteriores, Trabajo y la Secretaría General del Movimiento. La consecuencia de tal diseño fueron continuos conflictos de competencias y solapamientos que concluyeron con la desprotección de los trabajadores españoles.

Junto con las labores de asesoramiento, tampoco debe desdeñarse la estricta asistencia a los emigrantes incapaces de afrontar por sí mismos situaciones de desamparo por las que atravesaban. Fueron especialmente numerosos los casos de empleadas de hogar que, en no pocas ocasiones, producto de su limitado nivel cultural y de su aislamiento en el lugar de trabajo, fueron víctimas de abusos y vejaciones. Pero también trabajadores empleados en zonas aisladas, emigrantes sin recursos o de familias de fallecidos necesitados de repatriación. En esta tarea los agregados laborales no se encontraron solos, contando frecuentemente con la colaboración de miembros de la Sección Femenina o de sacerdotes de la Asesoría Eclesiástica de la DNS.

Pero los desvelos de la DNS hacia los emigrantes no estuvieron dedicados con exclusividad a garantizar su bienestar. Sin demérito de las actividades descritas hasta el momento, en el extranjero, la DNS pretendió continuar la función de encuadramiento político de los trabajadores que le competía en España. De esta forma, los agregados laborales participaron en la vigilancia, intentaron la represión e informaron puntualmente a sus superiores de las actividades contrarias al Régimen protagonizadas por los emigrantes españoles.

El agregado en Bruselas se distinguió por ser especialmente activo en estos menesteres, reconociendo con orgullo a sus superiores que los exiliados le "presentaban como un "Agente" de control e investigación fascista». Para el más efectivo ejercicio de tales actividades clasificó a la colonia española en diversas categorías (llegados antes de la guerra civil, exiliados republicanos moderados, componentes de las oleadas migratorias de los cincuenta,...), estableciendo para cada una de ellas una estrategia diferenciada. Los socialistas, mayoritariamente astu- 
rianos, fueron su objetivo preferente, dando puntualmente cuenta de su participación en manifestaciones o conflictos laborales. Su encono contra este colectivo alcanzó tal escala que el agregado llegó incluso a actuar contra los clubes de futbol que consideraba que se encontraban bajo su control. El principal instrumento de encuadramiento y control político puesto en práctica desde la agregaduría laboral fueron los llamados Hogares Españoles, centros sociales donde se asesoraba a los emigrantes, se impartían clase ${ }^{14}$, se recibía asistencia y se compartía el ocio con los compatriotas, recreando el ambiente de una patria lejana y mayoritariamente añorada. Pero el objetivo último de estos centros no fue otro que el control político de los trabajadores españoles $\mathrm{y}$, muy especialmente, de los mineros ${ }^{15}$. Controlados por la DNS, dirigidos desde las agregadurías laborales, imposibilitados para coordinarse entre sí, los Hogares perseguían aislar a la colonia española de un entorno social y político del pais de acogida que se consideraba, por democrático, pernicioso y susceptible de poner en cuestión el modelo de Estado vigente en España.

No obstante, es preciso reconocer el éxito de los Hogares Españoles en Bélgica. Se multiplicaron por todo el país, enclavándose preferentemente en las regiones mineras (donde mayor era la influencia socialista), agrupando a un número importante de personas, muchas de las cuales habían explícitamente manifestado reticencias a relacionarse con la embajada española o los consulados. No parece casual que ningún embajador español osara visitar las regiones carboníferas hasta que los Hogares comenzaron a funcionar. Incluso consiguieron superar boicots iniciales de grupos de exiliados. No en balde su popularidad les llevó a ser elegidos como interlocutores por las distintas administraciones belgas para la solución de algunos asuntos menores relacionados con la emigración.

La resultados cosechados en Bélgica animaron a trasladar la experiencia a Francia a finales de los años cincuenta, si bien se optó por una gradual puesta en práctica. En una primera fase, coordinados desde la agregaduría laboral, miembros de la Sección Femenina y de la Asesoría Eclesiástica de la DNS asistirían y asesorarían a los emigrantes, lo que concluiría con la constitución de Hogares de la Emigración. Una vez consolidada la actividad de los Hogares, éstos se transformarían en Casas de España, enclavadas en las regiones donde la presencia de emigrantes fuese más numerosa. El objetivo último de estas instituciones -que contaron con el apoyo del ministerio de Asuntos Exteriores y la aprobación en Consejo de Ministros- no dejaba lugar a dudas según lo expresado por el agregado laboral en París: 
«evitar y contrarrestar toda la acción de proselitismo político que actualmente se lleva por los sectores enemigos del Régimen» ${ }^{16}$.

Más allá del proyecto de las Casas de España, la actitud del agregado laboral en París fue menos pasional que la de su homólogo de Bruselas. Siempre se decantó por tácticas integradoras frente a una parte de los españoles antifranquistas antes que por una confrontación abierta con ellos. En contrapartida, exigió dirigir personalmente toda actividad política puesta en práctica hacia los emigrantes, impidiendo la actividad de los grupos falangistas que también salían de España en busca de trabajo. Tal voluntad no le impidió coordinarse con los cónsules españoles en Francia, en reuniones «ordenadas personalmente por el Ministro de Asuntos Exteriores", a las que asistieron también el Director de la Oficina de Información Diplomática y el agregado de prensa de la embajada.

El agregado laboral optó por políticas conciliadoras -lo que provocó no pocos enfrentamientos con sus superiores-, entendiendo que eran las más eficaces para restar influencia a los colectivos antifranquistas. Una de sus primeras propuestas consistió en facilitar la concesión de pasaportes a los exiliados que así lo solicitaran, siempre que no fueran conocidos activistas. Argumentaba el agregado que buena parte de la oposición existente se sustentaba sobre un amplio desconocimiento de la verdadera realidad española, alimentado torticeramente por los exiliados más activos. Por lo tanto, nada tendría una más positiva repercusión que impulsar a que se constatara sobre el terreno cuál era la auténtica situación económica y social del país. En este mismo sentido, el agregado elaboró una serie de propuestas, muchas de las cuales fueron puestas en práctica. Entre ellas, eximir a los hijos de los exiliados de las responsabilidades que pudieran derivarse de las actividades de sus padres, promover el programa Vacaciones en la Patria o impulsar la concesión de becas para estudiar en España, todas ellas con el propósito de contribuir el acercamiento entre los medios sociales ligados al exilio moderado o inactivo en Francia y el interior del país.

Las formas usualmente conciliadoras del agregado no deben conducir a engaño: su voluntad de combatir la disidencia fue inequívoca y no admite matices. De esta forma, intentó aprovechar sus relaciones institucionales con la administración francesa para forzar el cierre de los medios de comunicación ligados al exilio y dificultar las actividades de sus miembros más dinámicos. Asímismo, presionó con el fin de impedir las reuniones de los gobiernos republicano y vasco en el exilio, para que el Estado francés suprimiera todo subsidio del que se beneficiaran los huidos de la España franquista y exigió que las extradiciones solicitadas por el Régimen se atendieran de forma efectiva 
e inmediata. En modo alguno pudo deducirse de las actitudes del agregado un mínimo de comprensión o indulgencia hacia las actividades llevadas a cabo por los opositores al general Franco.

En otros Estados la voluntad de control y represión llevada a cabo desde las agregadurías laborales fue de menor intensidad. El agregado en Londres se mostró especialmente diligente para identificar e informar de la participación de emigrantes en las actividades contrarias al régimen franquista celebradas en 1960, con motivo de la visita de Castiella a la capital británica. En Alemania el agregado -no excesivamente activo en ninguno de sus cometidos- se limitó a entrar en contacto con un capellán de la policía germana que pretendía evitar la influencia comunista sobre los emigrantes españoles. El agregado laboral en Berna manifestó en repetidas ocasiones su preocupación por las demostraciones de antifranquismo protagonizadas por los españoles allí residentes. En todos los casos, no obstante, exiliados y emigrantes comprometidos con actividades contrarias al Régimen siempre fueron objeto de atención especial por los agregados laborales.

Debe hacerse una mención expresa a los intentos realizados desde las agregadurías laborales para impedir -o al menos dificultar- el contacto entre los emigrantes y las organizaciones sindicales de los países de acogida. No debe olvidarse, como se señaló anteriormente, que uno de los cometidos de los agregados consistía en mantener en el exterior la labor de encuadramiento confiada a la OSE en el interior de España. El agregado laboral en Bruselas (donde asturianos y catalanes mayoritariamente se afiliaban al sindicato socialista FGTB y los vascos al cristiano CSC) afirmó que inicialmente permitiría la sindicación a los españoles pero que, llegado el momento, acabaría con tal situación. El agregado en París no ocultó su malestar por la participación de españoles en conflictos obreros y, especialmente, por la vinculación de muchos de ellos con la filocomunista CGT.

Fue en Alemania y Suiza donde las fricciones alcanzaron un mayor nivel. La poderosa confederación sindical germana, DGB, acometió varias iniciativas tendentes a facilitar la integración laboral de los emigrantes españoles, al igual que acostumbraba a hacerlo con los de otras nacionalidades. Básicamente, las actividades se concentraban en informar sobre los derechos laborales vigentes en aquel país y favorecer el aprendizaje de unas nociones mínimas de su lengua, que contribuyeran a paliar la indefensión habitual de los trabajadores extranjeros que allí recalaban. Un número significativo de españoles se mostraron reacios a estos contactos, manifestando temor ante futuras represalias que pudieran esperarles al retornar a España. Ante tal situación la 
DGB pidió explicaciones al agregado laboral que negó cualquier posibilidad en tal sentido. Sin embargo, los informes remitidos desde la propia agregaduría en Bonn a sus superiores de la DNS confirmaban sin espacio para la duda lo expresado por los emigrantes a los sindicalistas alemanes.

Las relaciones entre el agregado laboral en Berna y la Unión Sindical Suiza también estuvieron empedradas de incidentes, provocados por los intentos de control político realizados desde la agregaduría y a las sospechas de represalias en caso de que los emigrantes decidieran unirse al sindicato. Sin embargo, el enfrentamiento de mayor trascendencia ocurrió tras la firma del convenio hispano-suizo de emigración que contemplaba la posibilidad de que organizaciones españolas -sin precisar cuáles- actuaran en Suiza con el propósito de ofrecer asistencia a los emigrantes. La confederación sindical creyó ver en esta disposición un subterfugio que permitiría la intervención de la OSE o de Falange, oponiéndose radicalmente a tal posibilidad, hasta el punto de hacer peligrar la ratificación del convenio. Finalmente pudo salvarse la situación mediante un canje de notas entre los gobiernos español y suizo donde se manifestaba expresamente que las organizaciones españolas tendrían una función exclusivamente asistencial.

Un caso singular de control político cuya responsabilidad recayó sobre la OSE tuvo por protagonistas a los miles de españoles que fueron repatriados de la Unión Soviética en 1957, operación que el Régimen transformó en una cuestión de prestigio pero hacia la que, al mismo tiempo, demostró tener no pocos recelos. La OSE fue encargada del «cuidado, tutela y adaptación» de los retornados, teniendo en cuenta que la mayor parte de ellos «no habian conocido otra educación que la del pueblo ruso, carente en absoluto de la formación cristiana del niño español». En suma, la Organización Sindical puso a disposición del Estado su vasta estructura tanto para facilitar la inserción laboral de los retornados como para vigilar su comportamiento. Los Delegados Provinciales de Sindicatos debieron informar a sus superiores sobre el entorno familiar y capacidades profesionales de aquellos, «indicando -a ser posible- si la ideología comunista prendió en él y en qué grado». Con los datos recabados se elaboraría un plan de ayuda para la obtención de trabajo y concesión de viviendas, siempre intentanto que el grupo quedara lo más disperso posible en todo el territorio español. El temor de las autoridades resultaba evidente: «ha de ser objeto de especial preocupación la posible actividad proselitista de algún repatriado cuyos relatos -verdades a medias- en ciertos casos, podrán influir en sectores de deficiente formación política, siempre propicios a dejarse seducir por quienes puedan especular sobre el bajo nivel de vida del trabajador español» ${ }^{17}$. 


\section{Intentos de instrumentalización de los emigrantes frente a terceros Estados}

Más allá del asesoramiento, asistencia o control político, durante los años cincuenta la OSE también intentó, al menos en dos ocasiones, utilizar a los emigrantes españoles como instrumentos de presión sobre los gobiernos de los países de acogida o sobre terceros Estados.

En 1953, facilitó la constitución del Sindicato de Trabajadores Españoles de Gibraltar y alentó sus movilizaciones. Razones laborales no faltaban para la protesta. Los cerca de 12.000 gaditanos y malagueños que allí trabajaban carecían de los más mínimos derechos: no eran beneficiarios de asistencia sanitaria, prestaciones por accidente, enfermedad o jubilación; tampoco se les reconocía el derecho de sindicación. Las jornadas podían llegar a las 90 horas semanales y, en algunas ocasiones, sólo a cambio de manutención y propinas. Aprovechando esta lamentable situación, la OSE promovió la convocatoria de una huelga aparentemente motivada por el descontento obrero. Sin embargo, el último y oculto fin estuvo en la voluntad de la Organización Sindical de importunar al Reino Unido ${ }^{18}$. Tal gravedad alcanzó el asunto que la OSE fue advertida por el gobierno español de que todo lo relacionado con Gibraltar era cuestión de Estado y que debía abstenerse de toda iniciativa hacia ese territorio sin consultar previamente, terminando con sus veleidades intervencionistas en la colonia británica.

De mayor envergadura fueron los proyectos que la OSE puso en práctica en Marruecos antes de su acceso a la independencia. En el enclave internacional de Tánger, aprovechando una importante presencia de empresas y trabajadores españoles, la OSE promovió la constitución de un sindicato títere: la Unión Sindical Tangerina (UST). Varios fueron los motivos que animaron esta decisión, pudiendo resumirse todos en la voluntad de controlar la fuerza de trabajo española que allí se encontraba. En primer lugar, para evitar la influencia de los sindicatos marroquíes y franceses que allí actuaban sobre los emigrantes españoles. Después, para preservar a las empresas españolas de la posible acción sindical de organizaciones no controladas por la OSE. Y, por último, porque la UST se concibió como el embrión de una organización mayor que, tras afianzarse en Tánger, ampliaría su ámbito de actuación al protectorado francés en el sur de Marruecos donde también trabajaban un considerable número de españoles. $\mathrm{Al}$ igual que en el caso de Gibraltar, las ambiciones de la OSE no se circunscribían fundamentalmente en el ámbito laboral: el objetivo principal era estructurar la colonia española con el fin de poderla utilizar 


\section{Ramón Baeza Sanjuán}

como instrumento de presión contra Francia, cuyas actitudes ocasionaban no pocos quebraderos de cabeza al régimen franquista. El esfuerzo fue finalmente baldío porque, antes de concluirse, Marruecos alcanzó la plena independencia ${ }^{19}$.

\section{Notas}

1 Relación de abreviaturas: AGA, Archivo General de la Administración; AISS, Administración Institucional de Servicios Socioeconómicos; SRE, Servicio de Relaciones Exteriores de la Delegación Nacional de Sindicatos (DNS); SG, Secretaría General de la OSE; VOS, Vicesecretaría de Ordenación Social; AMAE-R, Archivo del Ministerio de Asuntos Exteriores-Fondo Renovado.

2 La carencia de viviendas - con el consiguiente encarecimiento de las existentesalcanzó tales extremos que, en el sur-este de Madrid, podían encontrarse zonas donde los que llegaban desde zonas rurales habitaban literalmente en cuevas construidas y acondicionadas por ellos mismos. Así puede constatarse en informes elaborados por la propia Organización Sindical Española (vid. Visita a España de un representante sindical francés y de un periodista suizo, s.f. -atribuible a 1952-, AGA/AISS-SRE, R-2208).

3 El marco jurídico regulador de la emigración española en los primeros años cincuenta lo componían un Decreto de 11 de enero de 1946 relativo a la repatriación de ingresos (Tesoro del Emigrante) y una Orden de 20 de marzo por la que se fijaban los trámites del proceso migratorio bajo garantía y tutela del Estado español. Esta última norma no era más que la rehabilitación de la Ley y el Reglamento reguladores de la emigración de 1924, que fueron derogados por el Decreto de 1 de agosto de 1941 que creó el Consejo General de Emigración, y que, de hecho, impedían la emigración. Posteriormente, el 5 de enero de 1948, se adoptó una Orden que suprimía la exigencia de estar en posesión de un contrato de trabajo para solicitar el permiso para emigrar al extranjero.

4 Tenían competencias sobre distintos aspectos relacionados con la emigración al extranjero los ministerios de Asuntos Exteriores, Ejército, Marina, Educación Nacional, Gobernación, Trabajo y Secretaría General del Movimiento. En la concesión de pasaportes y visados también podían ejercer una influencia decisiva ayuntamientos, hermandades de agricultores y ganaderos y hasta los párrocos locales.

5 Vid. SECCIÓN DE POLf́TICA SOCIAL: «Emigración, política social y seguridad social», Cuadernos de Política Social nº45 (1960), pag. 40.

6 Una aproximación bibliográfica a la emigración como «válvula de escape» 0 "válvula de seguridad» de la España de los años sesenta puede encontrarse en RoDENAS CALATAYUD, Carmen: «Emigración y mercado de trabajo en España (1960-1985), Exils et migrations ibériques au $X X^{\text {me }}$ siècle $\mathrm{n}^{\circ}$ 3-4 (1997) págs. 139-140.

7 Vid. Organización Sindical Española: "Mociones», III Congreso Nacional de Trabajadores, Madrid, SNIPS, 1955, págs. 53-54.

8 El Instituto Español de Emigración fue creado por Ley de 17 de julio de 1956, quedando adscrito a la Presidencia del Gobierno. Por Decreto de 9 de mayo de 1958 quedó definitivamente encuadrado en el Ministerio de Trabajo. 


\section{Una aproximación a la imigración española hacia Europa...}

9 Con especial contundencia durante los años 1959 a 1961, la Secretaría General del Movimiento intentó que las competencias otorgadas al Instituto Español de Emigración fueran plenamente transferidas a las agregadurías laborales dependientes de la DNS. Nuevamente la oposición del ministerio de Trabajo contó con el inestimable apoyo de Exteriores para frustrar las pretensiones verticalistas. Un interesante conjunto de documentos que ilustran este enfrentamiento puede encontrarse en AMAE. R-7152/10, AMAE R-6228/100 y AMAE R-6227/8.

10 Así se deduce de la obra Delegación Nacional de Prensa, Propaganda Y RADIO DEL MOVIMIENTO: Aspectos humanos y sociales de la emigración, Madrid, Ediciones del Movimiento, 1961, pág. 26. En esta misma publicación puede encontrarse uno de los más pintorescos argumentos con los que se pretendió explicar el inicio de un nuevo éxodo migratorio español: "Yo no me atrevería a afirmar que el español emigra exclusivamente, o principalmente por motivos económicos. Para el español su propia tierra se le queda pequeña aunque viva bien en ella. Es como si una fuerza telúrica lo lanzara a recorrer caminos que en lo profundo de su sangre le son familiares. $Y$ a la sangre española, a causa de tantas y tan diversas culturas asimiladas, le son familiares casi todos los caminos del mundo», pág. 51.

11 Vid. Informe del letrado Francisco Casaurrán sobre la situación de los mineros en Bélgica, 23-III-1956, AGA/AISS-SRE, R-2248.

12 Sobre este asunto, resulta muy interesante la consulta de los siguientes documentos, elaborados por el agregado laboral en Francia: Informe 2377 sobre mano de obra en emigración temporal a Francia, 9-III-1956 e Informe sobre la emigración temporal de obreros españoles a Francia, 4-XII-1956, ambos en AGA/AISS-SRE, R-2420.

13 Discurso de Miguel García de Sáez ante el Jefe del Estado, (s.f., atribuible a 1956), AGA/AISS-SRE, R-2190.

14 Las clases que se impartían en los Hogares tenían una evidente intención doctrinal, pues no en balde eran de lengua, religión e historia. La decisión no era casual, el III Congreso Nacional de Trabajadores de la OSE, celebrado en 1955, refiriéndose a la política a desarrollar hacia los emigrantes había manifestado que debía "extremarse el contacto con los mismos y la vigilancia de su situación, fomentando la enseñanza de nuestro idioma, la práctica de nuestra religión y manteniendo vivo el sentido de nuestra unidad nacional de destino".

15 Así se reconocía en las notas informativas elaboradas por el agregado laboral en Bélgica en julio y agosto de 1959, que pueden consultarse en AGA/AISS-SRE, R-2198.

16 Vid. Acción político-social sobre las zonas de emigración española en Francia, VII-1960, AGA/AISS-SRE, R-2202.

17 Diferente documentación sobre este asunto puede consultarse en AGA/AISSVOS, R-1300.

18 Resulta tremendamente significativo que el artículo firmado por el Jefe del Servicio de Relaciones Exteriores de la DNS, Miguel García de Sáez, publicado en El Camagüeyano el 15 de marzo de 1953, tuviera como título La huelga de Gibraltar. Una batalla obrera contra el imperialismo inglés.

19 Sobre la intervención de la OSE en Marruecos, antes y después del acceso del país a la plena independencia existe un gran volumen de documentación en los fondos del Servicio de Relaciones Exteriores de la DNS. Entre las cajas más interesantes a consultar, podríamos citar las siguientes: R- 2197, R-2249, R-2210, R-2211, R-2265 y R-2416. 